\title{
DESLOCANDO A ESCOLA: OCUPAÇÃO E DESOCUPAÇÃO MBYÁ DA ESCOLA KARAÍ NHE'E KATU
}

EDUARDO SANTOS SCHAAN ${ }^{1}$

UFRGS

\begin{abstract}
RESUMO: A partir de uma oficina audiovisual com alunos da escola da Aldeia Nhundy, da parcialidade mbyá-guarani, faço uma reflexão sobre a escola indígena em relação à agência de alunos e professores mbyá. Os alunos deslocaram a realização das oficinas para domínios espaciais de suas vivências e evitavam permanecer em espaços e lógicas estatizantes presentes na escola. Essa desocupação da sala de aula produz novas relações de aprendizagem entre os alunos e eu. A presença do caminhar, como um relativo mbyá da predação, e da vontade individual são ressaltados. A agência dos professores indígenas mbyá também é refletida. Estes não podem se deslocar fisicamente da escola para escapar de sua força estatizadora. Assim, operam o segundo deslocamento tratado nesse texto, ocupando a escola com lógicas mbyá e estimulando a presença da comunidade em espaço escolar. Esses são dois modos de se deslocar e se desterritorializar das lógicas escolares de caráter colonial e disciplinar a partir da agência local mbyá.
\end{abstract}

PALAVRAS-CHAVE: escola indígena; aprendizagem; Mbyá-Guarani.

ABSTRACT: Instigated by an audiovisual workshop with students from Nhundy village, which belongs to the Mbyá-Guarani ethnic group, I reflect upon the indegenous school and the agency of the Mbyá students and teachers. The students dislocated the workhops to the spatial domains in which they are most used, avoiding state logics and spaces present on school. The abandon of the school class produces new learning relation between me and the students, and the presence of the walking-theme, as a Mbyá connection do predation, and the individual personality is highlighted. The agency of indigenous teachers is also reflected. Those cannot physically move out from the school to scape its state power. Thus, they operate the second dislocation treated in this text, occupying the school with Mbya logics and stimulating the presence of the community in school spaces. In these two ways, Mbya agency dislocates and deterritorializes the school colonial and disciplinary logics.

KEYWORDS: Indigenous school; learning; Mbyá-Guarani.

Durante os anos de 2014 e 2015 , realizei uma oficina audiovisual,

\footnotetext{
${ }^{1}$ Mestrando em Antropologia Social na UFRGS. E-mail: eduardo.schaan@gmail.com .
} 
que foi chamada de Projeto Ta'anga², em que compartilhei conhecimentos técnicos da área de captação de imagens com um grupo mbyá da tekoá Nhundy, especificamente para uma turma no final do Ensino Fundamental da Escola Estadual Karaí Nhe'e Katu. A tekoás Nhundy, ou Aldeia da Estiva, está localizada em Viamão (RS), na ERS 040, no km 39, e é formada por indígenas da parcialidade Mbyá, que compõem o grupo Guarani juntamente com os Nhandeva e Kaiowá (SCHADEN, 1974). Há, entretanto, moradores kaingang, presentes pela relação que os Mbyá de Nhundy possuem com aldeias kaingang do norte do estado, particularmente na Terra Indígena Guarita, localizada em Tenente Portela (RS). A escola na qual trabalhei é uma das poucas no estado que fornece, além do ensino fundamental, educação de nível médio para estudantes mbyá. As oficinas foram um modo de conhecer, ao longo de um ano, vivências que ocorriam no espaço escolar e, também, um modo de refletir sobre as formas de aprendizado mbyá que ocorreram durante a oficina. Relato inicialmente as oficinas e seu deslocamento de domínios feito pelos alunos e, posteriormente, reflito sobre um segundo deslocamento, que é o movimento dos Mbyá de ocupação da Escola Karaí Nhe'e Katu.

De modo bastante resumido, podemos afirmar que os MbyáGuarani são um povo que habita um território localizado entre o Paraguai, Argentina, Uruguai e a região meridional do Brasil, com uma população total, segundo Catafesto de Souza (2009), que soma cerca de 20 mil pessoas. No Rio Grande do Sul, existem aproximadamente 2.600 pessoas, que vivem em cerca de 83 lugares de ocupação (BAPTISTA DA SILVA e DIAS, 2013).

A tekoá Nhundy se concentra em um pequeno território de sete hectares, onde vivem cerca de 40 famílias em 33 casas, feitas em parceria entre a Funai e uma ONG estrangeira. Há um campo de futebol, bastante disputado, inclusive pelas mulheres, que formam um time próprio. Uma $O p y$, o espaço cerimonial mbyá, traduzida a mim como Igreja ou Casa de Rezas, foi construída em 2013. O terreno foi doado

\footnotetext{
2 "Imagem", em guarani (nome escolhido pelos participantes).

${ }^{3} \mathrm{O}$ termo tekoá é traduzido como aldeia, mas envolve um universo semântico mais amplo. Conforme Testa, tekoá "indica um espaço onde se tecem relações entre parentes de um grupo local" (TESTA, 2008, p. 294).
} 
pela prefeitura de Viamão há cerca de 17 anos. Anteriormente, as famílias viviam na Aldeia Gamelinha ( $y v y$ porã), em Tenente Portela, no norte do Estado, em uma terra que dividiam com grupos kaingang.

Construí a história da comunidade apenas em linhas gerais, pois, além de complexa, conheci-a em partes. As fontes mais importantes para entender as redes de parentesco e suas relações com a história da tekoá foram as conversas com os próprios moradores, o material reunido por Prates (2013) e também os materiais escolares, que, afixados na escola, indicavam brevemente a narrativa da própria comunidade sobre sua história.

Os fundadores da comunidade foram Juarez Gomez, hoje falecido, e sua esposa Talcira, e sua vinda do norte do Estado está relacionada a um sonho em que o casal decide se mudar para a região hoje habitada. Sua família extensa, no sentido utilizado por Benites (2012), passa alguns anos acampada às margens da ERS 040 e, posteriormente, obtém um acordo com o prefeito de Viamão, conseguindo a terra atual. Posteriormente, chegam mais irmãos e irmãs de Talcira, que em sua maioria permanecem desde então no local, e também vêm seus pais, Laurinda e Turíbio, por um breve período. Entre os filhos deste primeiro casal estão Cláudia, Talcira, Alzira, Genira, Pedrolina, Genilda, Tarcísio, Marcelino e Irineu. Uma das filhas do casal, Talcira, forma o núcleo familiar adulto com quem mais convivi, cujos integrantes são Gildo, atual cacique, Ivanilde, Leo, Everton, Zico, Aracy e Éllvis, incluindo seus filhos, parentes e cônjuges. Somente Éllvis está em idade escolar, sendo que os outros irmãos e irmãs têm atividades variadas, como estudantes universitários, professores e enfermeiros.

A Escola Karaí Nhe'e Katu se localiza no centro da área oficial da tekoá, e é uma homenagem a Juarez, esposo falecido de Talcira, significando "aquele que fala sábias palavras". A construção da escola dentro da própria aldeia, sendo bilíngue e com inspiração intercultural, foi iniciativa de Juarez, sendo sempre lembrada por seus filhos e parentes próximos. Atualmente são cerca de 15 professores, sendo quatro mbyá, que são Ivanilde da Silva, Eloir, Gildo da Silva e Agustinho Verá, que tratam do ensino da cultura guarani, do ensino das crianças menores e do letramento.

Retomando o relato das oficinas, sua intenção era que os 
indígenas, principalmente alunos da escola, tivessem condições técnicas para produzir imagens oriundas de aparelhos de captação de imagem e som, podendo construir suas autorrepresentações e suas formas de conhecimento através destas mídias. Uma clara inspiração foi o projeto "Vídeo nas Aldeias", coordenado por Vincent Carelli e por Dominique Gallois (1992). A autora escreve que o propósito daquele projeto era difundir mídias em áreas indígenas, formar tecnicamente novos cineastas e construir narrativas próprias à cada comunidade. Com base nesse projeto prévio, visando poder realizar essas oficinas, inicialmente planejei dividir as aulas em três momentos, centrados no aprendizado da fotografia, da sonografia e da cinematografia. As aulas teriam temas definidos em torno de aparelhos específicos ou estéticas determinadas. Em cada uma, haveria primeiro um esforço para refletir e teorizar sobre as imagens (sonoras ou visuais) e, a seguir, produzi-las de acordo com esse tema especificado em aula. Era uma divisão bastante clássica e enrijecida, como descobri posteriormente, que separava a teoria sobre um conteúdo, sua recepção e posteriormente sua produção, e foi recusada e remodelada pelos alunos. Olhando em retrospectiva, percebo um deslocamento que ocorreu originado pelos próprios alunos, e que pode ser relacionado às próprias lutas mbyá da Estiva em torno da escola, como tratarei adiante.

As aulas da oficina eram oferecidas em período extraclasse, no turno da tarde da Escola Karaí Nhe'e Katu. A turma era composta, principalmente, por alunos no final do Ensino Fundamental, com idades entre 10 e 16 anos, e reunia em média 10 alunos, geralmente meninos. No início dos encontros, houve uma curiosidade maior dos alunos devido à novidade oferecida, já que se interessam muito por fotografia, vídeo e informática, como pontuaram vários professores mbyá e não indígenas da escola.

No entanto, passados alguns encontros, as aulas se esvaziaram. Acredito que o fator principal para isto acontecer foi devido ao modelo de ensino que separava momentos de teorização e prática, que ocorriam principalmente em sala de aula. Havia fatores não imaginados a princípio, como quando dirigia perguntas à turma, em que os participantes respondiam geralmente em guarani para seus colegas, escolhendo os momentos em que traduziam para mim. O uso da língua 
guarani é uma questão complexa sob o prisma de uma atividade de ensino feita por um juruá (não indígena), pois os alunos fazem uma escolha de quando falar ou não em português, ou seja, quando se pode ou não entender o que eles estão falando. Isso criava, às vezes, empecilhos para o diálogo; em várias outras situações, contudo, as discussões em guarani eram mais esclarecedoras entre os próprios alunos, que podiam se comunicar mais livremente e compreender com mais rapidez. O segundo motivo que penso ter dificultado os primeiros momentos da oficina foi a recomendação da escola para me manter restrito à área escolar por sugestão da liderança da Estiva. Nas primeiras oficinas, os alunos se impacientavam e falavam "vamos sair!", "vamos na água!", de modo que, após algumas dessas exclamações, percebi que a saída era necessária para dar prosseguimento às aulas.

Para incluir, portanto, essa vontade dos alunos e um modo de aprender de sua preferência, conversei com Gildo Gomez, cacique da tekoá, pedindo permissão para adentrar em outros espaços da tekoá. Assim, as aulas ganharam novo fôlego. A separação entre teoria e prática se atenuou, pois os momentos de reflexão sobre as imagens, sua composição e seus aspectos técnicos aconteciam durante a atividade prática e não no limite físico da sala de aula. Após a saída da sala de aula, sucedeu que encontrei vários caminhos que eram próximos do cotidiano dos jovens e crianças, mas que diferiam momentaneamente por envolver um professor juruá. A sugestão de histórias a serem contadas começou a ser no centro da aldeia, seguida por caminhos que variavam segundo o roteiro pensado: o mato, o rio, o açude, uma casa vazia. Muitos estudantes que não estavam matriculados na escola ou não faziam parte formalmente da turma apareciam e participavam, o que tornava as presenças em aula dos alunos mbyá mais fluída e variável. Nem sempre havia um objetivo claro, por vezes os alunos desejavam somente passear, conversando, aprendendo novas técnicas, tirando fotos, fazendo perguntas.

Houve, ao longo dos meses em que ocorreu a oficina, uma transformação na metodologia de ensino e aprendizagem e que envolveu de modo capital o deslocamento. O momento da caminhada pelos espaços produzia uma modificação em meu papel de professor: os alunos aproveitavam para perguntar sobre minha família, a vida na 
cidade, namoros, festas, gostos musicais e outros assuntos. Outras vezes traziam logo possibilidades de histórias e dividiam-se quanto às funções, como operadores de câmera, de som, atores e diretores.

É importante frisar que havia maior participação e interlocução da turma quando ocorriam atividades lúdicas ou caminhadas pela tekoá e seus espaços adjacentes. Combinávamos, em geral, a gravação de algum filme com uma história que fosse criada pelos alunos. As histórias aconteciam durante 0 trajeto, com materiais sendo encontrados e recolhidos para a produção dos filmes: folhas de bananeira, algas, galhos, ossos, papelão, entre outros. A origem das narrativas produzidas pelo grupo, na maior parte das vezes, era uma lenda, como afirmavam, contada por pessoas mais velhas, fossem pais, mães, tios, avós. Essas histórias (e os seres que as povoam), eram trazidas pelos alunos e produzidas visualmente, ressaltando quem foi o responsável por a contar. Algumas vezes, quando eu perguntava o porquê de algum acontecimento na história recém-narrada, os alunos respondiam com frases como: "Isso tem que perguntar pros mais velhos. Eles é que sabem". As falas dos filmes eram sempre em guarani, e muitas vezes a reunião que antecedia a criação da história era feita com debates em guarani pelos estudantes. As histórias giravam sempre em torno de um contato com uma alteridade e de uma transformação dos atores humanos em mortos ou animais. $O$ processo de aprendizagem ocorria através da interlocução com diferentes pessoas e seres: eu próprio, como professor juruá, a influência dos espaços ao redor e dos seres extra-humanos que eram ficcionalizados.

Nesses caminhos pelo mato, longe do peso escolar, era possível aprender as técnicas audiovisuais enquanto se contavam histórias e enquanto todos se revezavam manuseando os equipamentos. A propósito, Baptista da Silva (2013, p. 45) escreve que "O mato [...] é o local onde estão presentes inúmeras alteridades extra-humanas que possuem vontade, propriedades imateriais, e com as quais é possível relacionar-se". Era um caminho sinuoso, em que o deslocamento se tornava um modo de aprender e de se relacionar com o cosmos mbyá. É caminhando que se chega aos destinos inalcançáveis a partir das salas quentes da escola, em que os perigos se colocavam a nossa frente: as cobras e aranhas, o perigo do ojepotá. 
A presença temática do ojepotá era marcante. O ojepotá é um ser relacionado a uma existência espiritual terrena (chamada de angue), que oferece perigo aos Mbyá e que circula às vezes nas adjacências da tekoá Nhundy. Inicialmente, os alunos traduziram para mim ojepotá como "possessão" ou "zumbi". Essa tradução foi substituída depois que falei que conhecia a palavra, que se tornou corrente em nossos diálogos. Os ojepotá, como narrados pelos alunos, eram resultado de algum mau comportamento por parte de uma pessoa, fosse criança, mulher ou homem. Esse comportamento poderia envolver caçar em um lugar inadequado, o que constitui o curta-metragem intitulado Os Caçadores. Neste, um grupo de três jovens vai ao mato caçar e passam por uma sepultura; dela surge um monstro, não definido especificamente, e que mata um caçador e espanta os outros dois. Em outro caso, a história consistia na transformação de um menino em sapo, transformação que ocorria depois de este urinar no lago. Em outra história, a mãe de dois meninos os alerta para não brincarem demais nas árvores; eles não a obedecem e se transformam em macacos. Em uma quarta história, um grupo de caçadores é atraído pelo canto de uma sereia e são levados por ela ao fundo das águas. Em cada situação se produzia um ojepotá específico, que significa esse agenciamento que transforma humano em alteridade extra-humana.

Como forma verbal reflexiva em terceira pessoa do singular, ojepotá significa uma transformação que está ocorrendo, e poderia ser traduzido como "se deixou desejar" (GUASCH, apud PRATES, 2013). O processo de ojepotá parece envolver em alguns casos um desejo passivo pela transformação, e não somente uma captura de uma alteridade ativa face a uma pessoa indefesa. O ojepotá envolve também um desejo da pessoa que se transformou de deixar de ser o que é, de ser seduzida pela alteridade, pelo estranho. A transformação resultava em seres macaco (ka'l), sereia (piragui), ou sapo, entre outros, que eram narrativizados em pequenos curtas-metragens. A inspiração cinematográfica para esses filmes, como se poderia imaginar, era os filmes de terror norte-americanos, como Hora do Pesadelo (1984). Quando a produção de filmes ou fotografias terminava, voltávamos à escola para o lanche dos alunos e às vezes se via um filme escolhido por eles. Esses geralmente envolviam o tema do terror ou da magia, apesar 
de que filmes indígenas também eram assistidos, como Bicicletas de Nhanderu (2011).

A saída da escola, como estamos percebendo, não implicou aulas mais rápidas, mais superficiais ou vazias. Na verdade, ocorreu o oposto: a produção de imagens se tornou mais interessante e rica. Também foi possível me estender mais sobre determinados assuntos, fazer explicações mais completas e variadas, além de poder dialogar melhor com os alunos. Viveiros de Castro (2002) resgata do Padre Antônio Vieira a metáfora das estátuas de mármore e de murta. O mármore, duro e trabalhoso, mas cuja forma se mantém estável aos séculos. E a murta, cuja aparente forma é rapidamente erigida, mas também rapidamente é corroída pelo tempo e pelos ramos que lhe saltam de sua forma tênue. Os índios tupinambá, que são o foco do autor neste trabalho, viveriam sob o signo da murta: a inconstante. Já a cultura ocidental, que imagino aqui em seu caráter iluminista de que trata Duarte (2012), estaria vinculada ao trabalho duro e permanente, cujas ideias e vontades sobrevivem ao tempo. Gildo, liderança da tekoá e professor da escola, fez várias vezes a mesma ressalva: o aprendizado é voluntário e depende do querer. A vontade dos estudantes é um sentimento e atitude ativos no processo de aprendizado mbyá, e produziria o que a nossos olhos é inconstância, mas que é condição mbyá para o aprendizado. A presença fluída de estudantes, a mudança de locais, as decisões conjuntas de atividades do dia seriam sinais que geram o efeito de inconstância na visão dos não indígenas, mas que estão imersos em práticas próprias relacionadas ao respeito à personalidade (SCHADEN, 1974). Esse autor já ressaltava como os Mbyá respeitavam cada personalidade, infantil ou adulta, pelo que é, vendo-a como divina e inata.

Penso que este conflito inicial em torno do espaço da sala de aula e de sua saída, operacionalizada pelos estudantes, está relacionado a uma tensão entre uma lógica disciplinar e uma lógica mbyá que privilegia a vontade de aprender e a autonomia da pessoa. Foucault (1979 e 1977) escreve sobre os "corpos dóceis" e as instituições estatais, inclusive a escolar. O autor argumenta que esta atua de forma a docilizar os indivíduos, cuja transformação acontece através de diversos mecanismos de poder, articulados em torno do mecanismo da 
disciplina. A disciplina seria responsável pela organização do espaço escolar, na manutenção do respeito e medo à figura altiva do professor, pela avaliação como condição à aprovação, etc. $O$ processo de disciplinarização fabrica o que o autor chama de corpos dóceis: corpos submissos ao poder estatal e que foram devidamente manejados para que comportamentos anormais fossem coibidos. Além disso, é o próprio poder estatal que define o que é a normalidade e quais os comportamentos adequados e quais são considerados anormais. A disciplina e a rede de poder que a sustenta seriam parte integrante da instituição escolar, inclusive do próprio professor, o agente estatal que a aplica. Esta aplicação, Foucault frisa, é direcionada ao corpo dos indivíduos, que introjetam em suas práticas os valores caros à disciplina e à ordem.

Essa disciplina se revela não apenas na normatização das práticas em sala de aula, mas também na normatização da sala de aula como única experiência legítima de ensino. É algo que Deleuze escreve sobre os processos de estatização:

As instituições [...] são práticas, mecanismos operatórios que não explicam o poder, já que supõem as relações e se contentam em "fixá-las" sob uma função reprodutora e não produtora. Não existe um Estado, apenas uma estatização [...] (DELEUZE, 2005, p. 83).

A escola configura-se como um espaço que fixa os indivíduos, tolhindo-os de suas capacidade agentivas e de outros espaços de aprendizagem. É uma visão que percebe essa instituição por seus aspectos repressores e reprodutores, que mantém lógicas estatais e capitalistas em operação. Em relação ao contexto indígena, também é possível aproximar-se das ideias de Lima (1995), que traça a história do Serviço de Proteção aos Índios (SPI). O SPI é criado com o intuito de levar, através da tutela, a civilização aos povos indígenas, que na época eram vistos como inocentes e infantis, e de fixar-lhes os valores morais e cívicos para construir uma Nação. Sobre o poder estatal, ele afirma que um de seus objetivos é: "[...] sedentarizar povos errantes, vencendo-Ihes - a partir de ações sobre suas ações e não da violência sua resistência em se fixarem em lugares definidos pela administrção 
[...]" (LIMA, 1995, p. 74, grifos no original). O Estado e suas práticas coloniais, como vemos, docilizaria e estatizaria o corpo dos estudantes, Ihes traria regras visando à construção de um determinado tipo de pessoa - o trabalhador naiconal. A escola indígena seria mais uma ferramenta de pacificação de povos e de sedentarização. Mas isso é só um lado da história.

A prática educacional centrada na sala de aula mostrou-se falha, como argumento nesse caso estudado, por envolver uma disciplina ocidental a que os Mbyá são pouco afeitos. Quando os alunos decidiram sair da escola para realizar suas aulas de aprendizagem audiovisual, evitaram um espaço marcado por uma determinada disciplina para seguir com suas lógicas próprias. Isso não quer dizer que não haja uma espécie de "disciplina" mbyá. O professor Eloir da Escola Karaí Nhe'e Katu afirmou, certa vez, que o cotidiano das crianças guarani fora da escola está relacionado a uma liberdade de movimentos e, à medida que a criança se torna adulta, a um controle dos atos individuais por parte da família. As crianças podem se deslocar como quiserem: caminhar pela estrada, pescar, sair e voltar de casa e, à medida que vão crescendo, passam por algumas interdições disciplinares - mas aqui, a disciplina é outra, voltada a uma construção de outro corpo, um corpo mbyá. A vontade da pessoa, no que tange ao deslocamento e à aprendizagem, continua sendo muito valorizada, e é justamente este um dos problemas enfrentados na escola.

Durante a mudança das oficinas de uma prática em sala de aula para uma prática nos arredores da tekoá, também é importante notar a alteração de domínios espaciais e cosmológicos. Se a escola é um ambiente originalmente juruá, o mato e seus caminhos adjacentes a tekoá são espaços mbyá, percorridos frequentemente por eles. De repente, era eu que estava fora de contexto, a disciplina típica do ambiente escolar já não funcionava e era eu que aprendia em meio às caminhadas e, do modo possível e improvisado às ocasiões, ensinava as técnicas fotográficas. Ao me transportar para esse domínio, os estudantes (que deixavam de ter um caráter de estudantes, pois se tornavam companheiros e guias de caminhada) também capturavam minha presença, me colocavam em uma rede de sociabilidade própria deles, sem a orientação das regras escolares. 
Esse processo de captura de presenças e conhecimentos é a própria predação da alteridade, de que Fausto (2002), entre outros, escreve. O autor afirma que os humanos e animais "estão imersos em um sistema sociocósmico no qual o objeto em disputa é a direção da predação e a produção do parentesco" (FAUSTO, 2002, p. 5). O relacionamento entre alteridades é permeado pela preocupação em evitar ser predado - o que, muitas vezes, está relacionado à perda do corpo humano e de suas características próprias (VILLAÇA, 2008). As cosmologias ameríndias, de maneira geral, estariam envoltas em um ciclo de predações e inconstância, em que existem possibilidades de se tornar outro (ser predado) ou de aproximar/interiorizar o outro dentro de si - o ojepotá, já citado, seria um caso mbyá típico de predação entre humanos e extra-humanos. As alteridades presentes nos diferentes espaços, como o mato, a cidade, o rio, não seriam inertes, mas dotadas de agentividade e de um perigo advindo de sua potência de transformar um tipo de corpo em outro através do ato de predar. Esse processo, geralmente associado às predações entre seres humanos e extra-humanos, entretanto, pode ser voltado ao próprio aprendizado e à produção da pessoa mbyá. A predação se torna uma forma de adquirir conhecimento, de englobar o outro e, no processo, alterar a si próprio. A já citada inconstância do aprendizado e sua contrapartida, a valorização da vontade e do movimento, aparecem também no plano cosmológico: a situação de ser humano pode ser transitória se não for devidamente mantida, e existe também a inconstância da pessoa em relação ao resto, nesse mundo de alteridades não mbyá.

Simultaneamente à questão da predação, era durante a caminhada que ocorria o aprendizado, que envolvia uma maneira cosmológica de lidar com os espaços e seres ao redor da aldeia, inclusive comigo próprio. É importante salientar que a noção de caminhada está relacionada à mobilidade em sentido amplo, pois o termo em guarani é - guatá (PRADELLA, 2009). Esse termo pode significar caminhar e viajar, ou seja, relaciona-se com curtas ou longas distâncias dependendo da situação contextual. Por isso, pode assumir nos textos antropológicos a forma de migrações, mobilidade ou caminhada, de acordo com o tema tratado por cada pesquisador. A caminhada guarani foi largamente estudada por vários autores, como Clastres (2003), Pissolato (2004), 
Garlet (1997), Pradella (2009), Catafesto de Souza (2009), entre outros. Pissolato (2004) escreve que os deslocamentos guarani são interpretados a partir de dois prismas: a busca pela Terra Sem Males e pelo foco da territorialização e desterritorialização. O primeiro enfoque lida com questões religiosas e cosmológicas, em que as caminhadas e mudanças dos Guarani estão ligadas a uma busca messiânica por uma terra perfeita. O segundo enfoque vê o território guarani como um espaço aberto que, ao longo da história, vai sendo continuamente ocupado ou desocupado como forma de organização social, de resolução de conflitos e produção de novas relações com novos seres e locais. Pissolato (2004) defende que os dois enfoques devem ser unidos, em que a mobilidade como dinâmica social e territorial implica processos cosmológicos relacionados à saúde e à religiosidade.

Inscrevo como fonte dessa citada inconstância e da vontade de sair, como diziam os alunos, a ideia de mobilidade (no sentido de -guatá) como impulso de desterritorialização, tratada tanto no sentido territorial, de saída de um espaço, como no sentido epistemológico, de saída da escola (e de suas lógicas estatizantes). Catafesto de Souza (2009), por exemplo, já apontava como a mobilidade mbyá foi uma estratégia cultural para escapar dos efeitos da colonização. O autor argumenta que se formulou uma estratégia que percebia que a colonização implica um processo de sedentarização, como também relata Lima (1995) e Oliveira Filho (1999). O território é perpassado por impulsos de territorialização e desterritorialização ao longo da história, mas que, ao mesmo tempo, têm estreitas conexões com aspectos cosmológicos. Clastres (2003) enfatiza este aspecto ao argumentar que as antigas migrações eram um modo de multiplicar as agências, de evitar o encapsulamento pelo Estado através de um movimento de dispersão demográfica e cosmológica. Pradella (2009) também relaciona de modo mais imediato a caminhada com modos de construir um corpo saudável e de possibilitar novos aprendizados entre os locais percorridos.

Neste texto, prefiro ver a caminhada como esse modo de deslocamento através da desterritorialização. Essa posição está contextualmente associada à relação dos estudantes com o ambiente escolar. A ideia do -guatá, que implica deslocamento, seria a máquina 
de guerra mbyá, a forma de evitar ser capturado pelas redes estatais (presentificadas na escola) e de estabelecer novas relações em outras localidades, como o mato e o açude próximos a tekoá Nhundy. A máquina de guerra, diz Deleuze, é a guerra usada como potência contra a Unidade, as formas de disciplinarização e estatização (DELEUZE e GUATTARI (1995). A máquina de guerra, é claro, é apenas uma imagem: ela se transforma, nesse caso, em imagem de deslocamento, mas penso que a potência da imagem permanece.

Um deslocamento físico, já que era no caminho que os alunos aprendiam e se divertiam, afastavam-se e voltavam, e ali que podíamos trocar experiências, gravar filmes e tirar fotografias. Mas também um outro deslocamento, não físico, mas também não menos real, ligado à própria mudança de domínios, de um domínio ligado aos juruá - a escola - e um domínio ligado aos Mbyá - o mato e a água. Se os espaços de mato e de rio são domínios mbyá, podemos perceber a mudança criada pelos próprios alunos, já que eles mobilizaram minha presença, como um ato de desterritorialização da escola. Um modo de evitar as regras escolares e sua disciplina ativa sobre os corpos mbyá e que me desterritorializava, produzindo novos afetos, novas experiências. O contexto era alterado, e as relações de produção de aprendizado também se alteravam. Os alunos, se é que se podia chamálos de alunos nessa nova situação, predavam meus conhecimentos em um novo contexto espacial e cosmológico do qual eles tinham domínio (mas eu não), enquanto também predavam as alteridades ojepotá por sua narrativização. Contar histórias é um modo de apreendê-las, de situá-las em regras narrativas que a organizam e possibilitam sua compreensão, como mostrou Lévi-Strauss (1975). Ocorria uma captura de conhecimentos técnicos, assim como uma forma de situar a alteridade extra-humana desses espaços de mato e de rio em um novo domínio, nesse caso digital.

Curiosamente, as imagens aqui elaboradas, condensadas na predação de alteridades e no impulso de escapar da disciplina ocidental através dos deslocamentos, estão relacionadas. A caminhada é a atualização do conceito de predação no caso mbyá e, ao mesmo tempo, um modo de evitar a captura de sua corporalidade pelos processos disciplinares não indígenas. É uma máquina de guerra complexa, pois 
consegue capturar o conhecimento ocidental e simultaneamente evitar a captura de seus próprios corpos, para não se docilizarem em demasia.

Ainda assim, há um segundo tema que passa por esse texto, e que parece mais um cenário deste, cuja agência é dos estudantes. 0 deslocamento que eles elaboraram foi um ato de virar o jogo político da educação, das formas de domínio da escola, que tem uma longa tradição colonial e uma longa tradição mbyá de sua evitação. A escola e sua situação na Aldeia da Estiva é o segundo deslocamento a ser tratado a seguir. Já vimos como os alunos mbyá evitaram essa disciplinarização nas oficinas audiovisuais deslocando-se, alterando os domínios espaciais e cosmológicos e as relações de poder entre professor e aluno. Essa foi uma agência dos alunos, entretanto. A segunda indagação é como os professores, pais e lideranças da tekoá Nhundy lidam com esse processo de estatização e se contrapõem a sua herança colonial.

A escola, enquanto instituição que durante muito tempo teve um objetivo colonial, um propósito de sedentarizar populações, de ensinarIhes a "civilização" (BERGAMASCHI e MEDEIROS, 2010; BENITES, 2012), recentemente passou por processos de apreensão por parte dos Mbyá e Kaingang do Rio Grande do Sul. A escola Karaí Nhe'e Katu especificamente foi fundada há menos de 20 anos por uma importante liderança local, Juarez Gomez, que sempre a viu como um modo de os conhecimentos juruá e mbyá se conectarem - em um processo que envolve suas próprias predações de conhecimentos e conflitos por causa da lógica escolar. Da escola, os Mbyá reclamam frequentemente de terem que lavar os pés à entrada (como se estivessem sujos), dos horários limitados para lanche, entrada e saída da escola, e da pouca flexibilidade para alterações de cronogramas e atividades. Essas são as disciplinarizações que cito anteriormente, e também se faz presente a visão da escola enquanto uma empresa colonial, em uma perspectiva próxima à de Lima (1995).

Precisamos, entretanto, perceber a escola Karaí Nhe'e Katu como um espaço mbyá e, ao mesmo tempo, juruá, pela presença de professores, de conteúdos e disciplina não indígenas. É um espaço de produção de novas relações. Ao oferecer as oficinas pude compreender um pouco da realidade da Escola, conhecendo os professores mbyá e juruá e algumas dinâmicas de funcionamento locais. Reflito, nesse 
momento, sobre um segundo deslocamento que acontece na Escola Karaí Nhe'e Katu: a escola se desloca da escola. Se a instituição escolar tem uma tradição disciplinar ocidental e uma herança colonial, é um projeto que os Mbyá sabem que precisam evitar. Simultaneamente, há um desejo de várias lideranças, como de Talcira e seu falecido esposo Juarez, de poder apreender esses conhecimentos não indígenas como forma de fortalecimento do grupo. É um projeto de escola que se afasta de outro, é esse deslocamento que os Mbyá desejam produzir, mantendo os objetivos escolares próximos aos objetivos da comunidade. Mas a predação dessa instituição não pode ocorrer por um deslocamento no sentido espacial - uma desocupação - como os jovens mbyá fizeram nas oficinas audiovisuais e associada à estratégia de desterritorialização a partir do caminhar (-guatá). No caso da escola, o deslocamento é feito através de uma ocupação feita pelos professores, suas famílias e a comunidade da Nhundy de modo geral.

Antes de continuar, é importante salientar que houve um longo processo de formação de professores indígenas no Rio Grande do Sul e também na Nhundy em especial, e que, ainda em curso, tem desembocado em questionamentos das epistemologias escolares não indígenas, como seu calendário, horário, conteúdos programáticos, entre outros. Esse processo tem sido condensado atualmente na Rede de Ação Saberes Indígenas na Escola (Núcleo UFRGS), vinculada ao MEC/SECADI, e realizada por um conjunto de instituições universitárias, como UFRGS e ULBRA, e professores das áreas de Educação, Música, Antropologia Social, Literatura, entre outros. O objetivo da Rede é formar professores e possibilitar que epistemologias próprias de cada localidade e povo indígena sejam transpostas à sala de aula. A Rede congrega centenas de professores kaingang e mbyá nesses cursos, que envolvem longas discussões e atividades de pesquisa e reflexão. $\mathrm{Na}$ Estiva, a importância da Rede é patente, e também está vinculada a um modo utilizar a escola como um espaço de mobilização para lutas políticas.

Quando se fala de escola mbyá, a imagem de "portal" é recorrente em diversas falas de professores e lideranças indígenas ligados à educação. É uma forma de perceber a interculturalidade, frequentemente citada pelos acadêmicos não indígenas nos encontros 
da Rede de Saberes. Implica um arranjo local entre as práticas e saberes mbyá e os saberes juruá ocidentais. Como Benites (2012) escreve em relação aos Avá Kaiowá, na aldeia da Estiva acontece um processo semelhante: cada família tem um estilo próprio, que é passado pela formação das crianças, por reprimendas, conselhos, hábitos comuns, criando uma unidade familiar. O autor também afirma que cada família e cada aldeia, a partir desse estilo próprio, tem um modo de se aproximar ou de se afastar de políticos, antropólogos, educadores, missionários.

$\mathrm{Na}$ Nhundy, e possivelmente nas outras escolas mbyá, há uma apreensão determinada da escola, que produz novas relações entre a comunidade e suas mobilizações, mas que ocorre de forma diferenciada devido ao próprio contexto variável de aspirações da comunidade, da presença de professores indígenas e da formação dos mesmos. $\mathrm{Na}$ Escola Karaí Nhe'e Katu, a liderança Talcira, mãe do professor e cacique Gildo e da professora e estudante de pedagogia na UFRGS Ivanilde da Silva, frequentemente ressalta sua percepção de que os Mbyá devem aprender os conhecimentos externos juruá como forma de fortalecer os próprios Mbyá.

Lembro que, recentemente, um projeto de contação de histórias foi aplicado na Nhundy. Houve algumas reclamações posteriores, entretanto, por parte de lideranças mbyá de que o projeto não foi bom. O motivo é que não deu um retorno para a aldeia, como afirmou Gildo. Esse retorno não está relacionado a uma questão monetária, mas principalmente à reciprocidade durante a construção e elaboração dos projetos, como a troca de saberes. A crítica feita também lembra que o estabelecimento de trocas de saberes e de materiais são importantes para se considerar uma relação boa ou não. A escola pode estar situada nessa mesma percepção, em que precisa haver uma troca efetiva entre os dois lados. A escola é uma fonte importante de relação com conhecimentos e instituições do mundo juruá, e ao mesmo tempo altera a vida cotidiana da comunidade - os dias em que não há aulas são vividos com um certo alívio e mais atividades em comum.

O processo de reformulação e reposicionamento da escola, de uma perspectiva colonial para uma perspectiva indígena e mobilizadora, ainda em curso, foi bastante explicitado por Gildo Gomez. Em maio de 2016, houve uma série de ocupações de escolas gaúchas por estudantes 
secundaristas com pautas reivindicatórias de seus direitos e de melhorias para a educação pública. Perguntei a Gildo, brincando, se os estudantes da Escola Karaí Nhe'e Katu não iriam ocupar a escola. Sua resposta foi "Mas já está ocupada!". A ocupação, para usarmos a linguagem recente das mobilizações políticas não indígenas, é um processo que já ocorre de formas próprias nas escolas indígenas.

As ocupações, na prática, ocorrem de maneira variada e geralmente em eventos cotidianos. Algumas vezes, entretanto, essa posição é tornada propositalmente visível, externalizando a ocupação mbyá da escola. Um desses momentos é a Noite Cultural, que já ocorre há dois anos na Nhundy, tendo acontecido mais recentemente em maio de 2016. É um projeto de apresentação da cultura mbyá-guarani de acordo com os Mbyá da tekoá, em que estão presentes o artesanato, as músicas tradicionais, o coral, as falas com os tuja'i (velhinhos), as ervas medicinais, a pintura com o urucum, entre vários outros objetos e eventos. O projeto é organizado por professores e comunidade dentro da escola ao longo de um dia inteiro, e a ele comparecem em peso os moradores da Nhundy, além de algumas pessoas de tekoá vizinhas. 0 público-alvo, entretanto, é principalmente os não indígenas: são convidados políticos, professores, antropólogos, universitários, agentes de saúde, entre outros. O objetivo - explicitado durante o próprio encontro - é demarcar a presença da comunidade mbyá dentro da Escola Karaí Nhe'e Katu, insistindo que é, sim, uma escola mbyá. Uma comprovação emblemática para esse fato é a construção de uma $O p y$ (casa de rezas) "de mentira", como foi citado, no terreno escolar. O propósito era colocar uma imagem da $O p y$ verdadeira dentro da própria escola, ressaltando a presença efetiva da religiosidade e do modo de viver (-reko regua) mbyá dentro das salas de aula e, ao mesmo tempo, permitindo que os juruá pudessem ver a $O p y$ (cuja entrada é vetada a pessoas não mbyá), mesmo que somente sua cópia, por dentro. 0 evento e a construção da Casa de Rezas em terreno escolar já seriam uma ocupação. Mas ocorre uma segunda, mais inusitada: após a construção, Talcira, liderança da comunidade e também idealizadora da Escola, passou a dormir dentro da construção, pois sua arquitetura tradicional the era mais adequada e atraente. A imagem copiada da Casa de Rezas se convertia somente em casa, e cria uma circularidade na 
relação da comunidade com a escola local: de idealizadora de uma escola imaginada como portal, passando a residir no próprio ambiente escolar, agora convertido em espaço mbyá ocupado.

\section{Considerações finais}

O primeiro deslocamento envolve, nesse texto, uma mudança da aprendizagem da sala de aula para os espaços de mato e rios, em um percurso (des)centrado no caminho e que envolvia uma maneira cosmológica de lidar com os espaços e seres ao redor da aldeia. Minha presença como professor foi deslocada ao se mudar de contexto, e as relações de ensino e aprendizado foram modificadas e se simetrizaram em alguma medida. Durante a mudança das oficinas de uma prática em sala de aula para uma prática nos arredores da tekoá, é importante notar a alteração de domínios espaciais. Se a escola é um ambiente originalmente juruá, o mato e seus caminhos adjacentes à tekoá são espaços mbyá, percorridos frequentemente. Mas, ao mesmo tempo, nesse caminho eram feitos contatos com a alteridade extra-humana, e ali os Mbyá a predavam - no lugar de serem predados por ela -, exercendo uma espécie de controle através da narrativa. Estávamos imersos em uma rede sociocósmica de predação, como diria Fausto (2002). A alteração de domínios gerava um embotamento das relações convencionais entre professor e aluno - o que suscitou essa reflexão e produzia novas relações com os espaços percorridos.

O que ainda constitui e envolve essa rede de ideias é o fato de as histórias sobre as alteridades e as transformações de humanos em extra-humanos terem sido contadas por parentes mais velhos desses jovens, como pais, avós ou tios. E a maior parte dos pais e avós estava envolvida na ocupação da Escola Karaí Nhe'e Katu. Essa ocupação da escola se torna física em alguns momentos, como na Noite Cultural que aconteceu em maio de 2016, quando a comunidade e os próprios alunos ocuparam a escola à noite, convidando os juruá (acadêmicos, parceiros, professores, agentes estatais) para assistirem à sua performance e ao fortalecimento de sua escola.

São modos diferentes de deslocamento, um pela via da 
desocupação e outro pela via da ocupação. Os alunos desocupavam a escola, desterritorializavam o espaço escolar. A autoridade de um professor era esvaziada, relativamente, quando entrava no domínio mbyá, que envolve regras de sociabilidade e aprendizagem próprias, além de um modo de predação de alteridades extra-humanas e não mbyá. Ao mesmo tempo, os professores e suas famílias extensas faziam seu próprio deslocamento (mas esse já ocorria há mais tempo) da escola enquanto instituição disciplinar e colonial, para uma escola que seja um instrumento de luta para os Mbyá. Como falam os Mbyá frequentemente, a palavra norteadora é - mbaereté, fortalecimento.

\section{Referências bibliográficas}

BAPTISTA DA SILVA, Sergio. Cosmo-ontológica mbyá-guarani: discutindo o estatuto de "objetos" e "recursos naturais". Revista de Arqueologia, Belo Horizonte, v. 1, n. 26, p. 42-54, 2013.

BAPTISTA DA SILVA, Sergio; DIAS, Adriana. Seguindo o fluxo do tempo, trilhando o caminho das águas: territorialidade guarani na região do lago Guaíba. Revista de Arqueologia, Belo Horizonte, v. 1, n. 26, p. 56-70 , 2013.

BENITES, Tonico. A escola na ótica dos Ava Kaiowá: impactos e interpretações indígenas. Rio de Janeiro: Contra Capa, 2012.

BERGAMASCHI, Maria Aparecida; MEDEIROS, Juliana História. Memória e tradição na educação escolar indígena: o caso de uma escola Kaingang. Revista Brasileira de História, São Paulo, v. 30, n. 60, p. 55-75, 2010.

BICICLETAS de Nhanderu. Direção: Ariel Ortega e Patrícia Ferreira. Produção: Olívia Sabino e Patrícia Ferreira, Vídeo nas Aldeias, 2011. Brasil. 1 DVD, 45 min. son. color.

CLASTRES, Pierre. A sociedade contra o Estado. São Paulo: Cosac \& Naify, 2003.

DELEUZE, Gilles. Foucault. São Paulo: Brasiliense, 2005.

DELEUZE, Gilles; GUATTARI, Félix. Mil Platôs: capitalismo e esquizofrenia. Rio de Janeiro: Editora 34, 1995.

DUARTE, Luiz Fernando Dias. O paradoxo de Bergson: diferença e holismo na 
antropologia do Ocidente. Mana, Rio de Janeiro, v. 18, n. 3, p. 417-448, 2012.

FAUSTO, Carlos. Banquete de gente: comensalidade e canibalismo na Amazônia. Mana, Rio de Janeiro, v. 8, n. 2, p. 7-44, 2002.

FOUCAULT, Michel. Vigiar e punir: nascimento da prisão. Petrópolis: Vozes, 1977.

Microfísica do poder. Rio de Janeiro: Edições Graal, 1979.

GALLOIS, Dominique; CARELLI, Vincent. "Vídeo nas aldeias": a experiência Waiãpi. Cadernos de Campo, São Paulo, v. 2, n. 2, p. 25-56, 1992.

GARLET, Ivori José. Mobilidade Mbyá: história e significação. 1997. 221 f. Dissertação (Mestrado em História) - PUCRS, Faculdade de Filosofia e Ciências Humanas, [1997].

HORA do pesadelo, A. Direção: Wes Craven. Produção: Robert Shaye - New Line Cinema, Estados Unidos, 1984. 1 DVD (92 min). son. color.

LÉVI-STRAUSS, Claude. A eficácia simbólica. In: Antropologia estrutural: Rio de Janeiro: Tempo Brasileiro, 1975. p. 215-236.

LIMA, Antonio Carlos Souza. Um grande cerco de paz: poder tutelar, indianidade e formação do Estado no Brasil. Petrópolis: Vozes, 1995.

OLIVERIA FILHO, João Pacheco de. Entrando e saindo da "mistura": os índios nos censos nacionais. In: Janeiro: UFRJ, 1999. p. 124-154.

PRADELLA, Luís Gustavo. Jeguatá: O caminhar entre os guarani. Espaço Ameríndio, Porto Alegre, v. 3, n. 2, p. 99-120, jul./dez. 2009.

PRATES, Maria Paula. Da instabilidade e dos afetos: pacificando relações, amansando outros: cosmopolítica guarani-mbyá (Lago Guaíba/RS-Brasil). 2013. 317 f. Tese (Doutorado em Antropologia Social) - UFRGS, PPGAS, [2013].

SCHADEN, Egon. Aspectos fundamentais da cultura guarani. São Paulo: EPU, 1974.

CATAFESTO DE SOUZA, José Otávio. Os Mbyá-Guarani e os Impasses das Políticas Indigenistas no sul do Brasil. VIII Reunião de Antropologia do Mercosul "Diversidade e Poder na América Latina". Buenos Aires, Argentina. de 29 de setembro a 02 de outubro de 2009.

CATAFESTO DE SOUZA, José Otávio; MORINICO, José Cirilo Pires. Fantasmas das brenhas ressurgem nas Ruínas: Mbyá-Guranis relatam sua versão sobre as missões e depois delas. In: BOEIRA, Nelson; GOLIN, Tau (Org.). História geral do Rio Grande do Sul 5: Povos indígenas. Passo Fundo: Méritos, 2009. p. 301-330. 
PISSOLATO, Elizabeth. Mobilidade, multilocalidade, organização social e cosmologia: a experiência de grupos Mbyá-Guarani no sudeste brasileiro. Tellus, Campo Grande, v. 4, n. 6, p. 65-78, 2004.

TESTA, Adriana. Entre o canto e a caneta: oralidade, escrita e conhecimento entre os Guarani Mbyá. Educação e Pesquisa, São Paulo, v. 34, n. 2, p. 291-307, 2008.

VILLAÇA, Aparecida Maria. Conversão, predação e perspectiva. Mana, Rio de Janeiro, v.14, p. 173-204, 2008.

VIVEIROS DE CASTRO, Eduardo. A Inconstância da Alma Selvagem e Outros Ensaios de Antropologia. São Paulo: Cosac \& Naify, 2002.

Recebido em: 06/10/2016 * Aprovado em: 24/12/2016 * Publicado em: 30/06/2017 